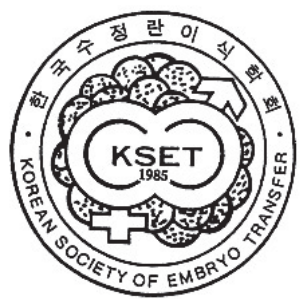

\title{
Effects of Temperatures and Basal Media on Primary Culture of the Blastomeres Derived from the Embryos at Blastula Stage in Marine Medaka Oryzias Dancena
} Jae Hoon Choi ${ }^{1}$ and Seung Pyo Gong ${ }^{1,2,+}$

${ }^{1}$ Department of Fisheries Biology, Pukyong National University, Busan 48513, Korea

${ }^{2}$ Department of Marine Biomaterials and Aquaculture, Pukyong National University, Busan 48513, Korea

\section{Abstract}

Although the efforts to establish fish embryonic stem cells (ESCs) have been made for a long time, derivation of authentic ESCs that possess pluripotency is still difficult suggesting a need for the stepwise optimization of the methods to establish fish ESCs. Primary culture of the blastomeres from the embryos at blastula stage is a critical step for establishing continuous ESC lines. Here, we evaluated the effects of temperatures and basal media on primary culture of blastula embryo-derived blastomeres in marine medaka (Oryzias dancena). The blastomeres were isolated from the blastula embryos and cultured in various conditions designed by the combination of 4 temperatures including $28^{\circ} \mathrm{C}, 31^{\circ} \mathrm{C}, 34^{\circ} \mathrm{C}$, and $37^{\circ} \mathrm{C}$ and 2 basal media including Dulbecco's modified eagle's medium (DMEM) and Leibovitz's L-15 medium (L15). With the exception of a case cultured in $\mathrm{L} 15$ at $31^{\circ} \mathrm{C}$, the rate of primary cell adherence reached $100 \%$ when the blastomeres were cultured over $31^{\circ} \mathrm{C}$. The period for primary adherence was significantly shorter in the groups cultured in $34^{\circ} \mathrm{C}$ and $37^{\circ} \mathrm{C}$ than in the ones in $28^{\circ} \mathrm{C}$ and $31^{\circ} \mathrm{C}$. The proportion of subculture was significantly high in the group cultured in DMEM at $31^{\circ} \mathrm{C}$ compared to the other groups. Collectively, we demonstrated that the culture in DMEM at $31^{\circ} \mathrm{C}$ was effective to primary culture of the blastomeres derived from blastula embryos.

Received : 15 December 2018

Revised : 20 December 2018

Accepted : 23 December 2018

Key Words : Blastomere, Blastula Embryo, Primary culture, Temperature, Media

† Correspondence: Seung Pyo Gong (ORCID: 0000-0002-9358-9568)

Tel: +82-51-629-5912, Fax: +82-51-629-5908

E-mail address: gongsp@pknu.ac.kr 


\section{INTRODUCTION}

Embryonic stem cells (ESCs) in mammals mean the cultured cells which are derived from the inner cell mass of blastocyst. They can self-renew and differentiate into any types of cells comprising the body (Evans and Kaufman, 1981; Martin, 1981; Bradley et al., 1984), which made them a valuable material for biomedical science. In addition, ESCs are able to contribute to the production of transgenic animals as a tool for cell-mediated gene delivery (Robl et al., 2007). Likewise, fish ESCs can also be utilized as a material for cell-mediated gene delivery for the production of transgenic fish and a model for biomedical researches (Hong et al., 1998; Yasui et al., 2011). In 1996, establishment of fish ESCs was first reported in a teleost fish, Japanese medaka (Oryzias latipes) (Hong et al., 1996). Afterward, many studies regarding ESC establishment have been reported in various fish species including gilt-head bream (Bejar et al., 2002), red sea bream (Chen et al., 2003), marine flatfish (Holen and Hamre, 2004), rohu (Goswami et al., 2012), Indian catfish (Barman et al., 2014), zebrafish (Ho et al., 2014), Asian sea bass (Parameswaran et al., 2007), sea perch (Chen et al., 2007), Indian major carp (Dash et al., 2010), Atlantic cod (Holen et al., 2010), and Nile tilapia (Fan et al., 2017). However, most of those cells was ESC-like cells rather than ESCs because they could not satisfy all of the criteria for ESCs (Bejar et al., 2002; Chen et al., 2003; Holen and Hamre, 2004; Chen et al., 2007; Parameswaran et al., 2007; Dash et al., 2010; Holen et al., 2010; Goswami et al., 2012; Barman et al., 2014; Fan et al., 2017) indicating that additional studies should be performed to establish genuine pluripotent fish ESCs. Marine medaka (Oryzias dancena) is a good experimental model fish like Japanese medaka and zebrafish due to its property to spawn daily, short generation time, easy maintenance in a laboratory scale, and ability to acclimate to a a wide range of salinity as the euryhaline species (Inoue and Takei, 2003; Cho et al., 2010). We previously established ESC-like cells in O. dancena (Lee et al., 2013; Lee et al., 2015) that showed alkaline phosphatase activity and the abilities to form embryoid bodies and differentiate in vitro into various cell types (Lee et al., 2015). But, they showed very low chimeric contribution when introduced in developing embryos and a lack of expression of several pluripotency-regulatory genes (unpublished observation). Therefore, the efforts to establish pluripotent ESCs in $O$. dancena are persistently needed. For derivation of fish ESCs, there are sequential steps including induction of fertilization, collection of blastula embryos, isolation of blastomeres, primary culture of blastomeres, and establishment of stable cell lines followed by characterization of ESC properties. In these procedures, the steps up to isolation of blastomeres are quite normal and thus do not affect the next steps significantly if there is no microbial contamination. In contrast to this, the step for primary culture of blastomeres is critical because the cells derived from this step are the founder of the future stable cell lines. However, the optimal conditions for this step have not been studied well for fish ESCs, thereby indicating that it should be determined by further studies. In this study, we evaluated the effects of temperatures and basal media on primary culture of blastomeres derived from $O$. dancena embryos at blastula stage to find the optimal conditions. Temperature and medium greatly contribute to cellular physiology in fish cell culture (Lannan et al., 1984; Freshney, 2010). Thus, optimization of the two factors is quite important. In fish cell culture, Leibovitz's L-15 medium (L15), which is originally designed for the use in air atmosphere, is a widely used basal media since the culture condition for fish cells has been traditionally optimized without $\mathrm{CO}_{2}$. However, most studies regarding fish ESC culture have used Dulbecco's Modified Eagle's Medium (DMEM) containing HEPES for $\mathrm{pH}$ control in non- $\mathrm{CO}_{2}$ environment perhaps according to the first report of ESC derivation (Hong et al., 1996). Therefore, we cultured $O$. dancena blastula embryo-derived blastomeres in various culture conditions that varied in temperatures $\left(28^{\circ} \mathrm{C}, 31^{\circ} \mathrm{C}, 34^{\circ} \mathrm{C}\right.$ and $\left.37^{\circ} \mathrm{C}\right)$ and basal media (L15 and DMEM), and subsequently investigated the efficiency of primary cell adherence and initial culture according to culture conditions.

\section{MATERIALS AND METHODS}

\section{Fish}

Fish were maintained in the Laboratory of Cell Biotechnology, Pukyong National University (Busan, Korea). Sexually matured male and female $O$. dancena were raised by a ratio of $1: 3$ in $20 \mathrm{~L}$ water tanks for collecting the embryos. Water temperature and salinity were kept at $25 \pm 1^{\circ} \mathrm{C}$ and 5 psu, respectively, and photoperiod was maintained as $14 \mathrm{~h}$ light and $10 \mathrm{~h}$ dark throughout the experiments. The fish were fed particulate feeds of $500 \mu \mathrm{m}$ (EWHA, Busan, Korea) and the larvae of brine shrimp (Artemia Nauplius). All procedures dealing with animals complied with the guidelines provided by Pukyong National University and the Institutional Animal Care and Use Committee (IACUC) of Pukyong National University approved our research proposal (approval number: 2016-07). 


\section{Primary culture of the blastomeres from blastula embryos}

Ten embryos at blastula stage were used for isolation of blastomeres. The embryos were washed with Dulbecco's PhosphateBuffered Saline (DPBS; Gibco, Grand Island, NY) and sterilized by immersing them into $70 \%$ ethanol for $10 \mathrm{sec}$. After being washed three times with DPBS, the embryos were ruptured by fine needles within $200 \mu \mathrm{L}$ DPBS drop on a $35 \mathrm{~mm}$ petri dish (SPL Life Science, Pocheon, Korea). The scattered blastomeres were collected by centrifugation at $400 \mathrm{~g}$ for $2 \mathrm{~min}$ and after that, they were re-suspended with $500 \mu \mathrm{L}$ culture media and seeded on a well of 48 well cell culture plates (SPL Life Science), which were coated with $0.1 \%(\mathrm{w} / \mathrm{v})$ gelatin (Sigma-Aldrich, St. Louis, MO). Two types of culture media were used in this study. One was DMEM (Gibco, Cat No: 10564) supplemented with 1\% (v/v) non-essential amino acid (Gibco), 15\% (v/v) fetal bovine serum (FBS; Cellgro, Manassas, VA), 1\% (v/v) fish serum (Caisson Laboratories, Smithfield, UT), $50 \mu \mathrm{g} / \mathrm{mL}$ embryo extract, $1 \%$ (v/v) penicillin-streptomycin mixture (Gibco), $10 \mathrm{ng} / \mathrm{mL}$ recombinant human basic fibroblast growth factor (bFGF; Gibco), $100 \mu \mathrm{M} \beta$-mercaptoethanol (Gibco), $2 \mathrm{nM}$ sodium selenite (Sigma-Aldrich), and $1 \mathrm{mM}$ sodium pyruvate (Gibco). Final concentration of HEPES in DMEM was adjusted to $20 \mathrm{mM}$. The other was L15 (Gibco, Cat No: 11415) containing same types and concentrations of supplements with DMEM. The seeded blastomeres were cultured in $28^{\circ} \mathrm{C}, 31^{\circ} \mathrm{C}, 34^{\circ} \mathrm{C}$, or $37^{\circ} \mathrm{C}$ incubator with an air atmosphere. For subculture, the cells were treated with $0.05 \%$ trypsin-EDTA (Gibco) and collected by centrifugation at $400 \mathrm{~g}$ for $4 \mathrm{~min}$. Then the cells were split into 1:2 ratio and cultured in new culture wells coated with $0.1 \%$ gelatin.

\section{Preparation of embryo extract}

The embryos were collected within $1 \mathrm{~h}$ after fertilization. After removal of attachment filaments of the embryos, they were cultured in distilled water, which was adjusted to $5 \mathrm{psu}$ and supplemented with $0.00001 \%(\mathrm{w} / \mathrm{v})$ methylene blue (Acros organics, Morris Plains, NJ), at $25 \pm 1^{\circ} \mathrm{C}$. When the embryos developed to blastula stage ( $8 \mathrm{~h} 30 \mathrm{~min}$ after fertilization), they were washed twice with DPBS and stored at $-77^{\circ} \mathrm{C}$. Developmental stages of the embryos were referenced by Song et al. (2009). To collect embryo extract, 400-1000 embryos were thawed and homogenized in $1 \mathrm{~mL}$ DPBS in ice. The homogenate was frozen and thawed three times in $-196^{\circ} \mathrm{C}$ liquid nitrogen and a $37^{\circ} \mathrm{C}$ water bath and centrifuged at $3,500 \mathrm{~g}$ for $30 \mathrm{~min}$ at $4^{\circ} \mathrm{C}$. The supernatant was retrieved and additionally centrifuged at 18,000 $\mathrm{g}$ for 40 $\min$ at $4^{\circ} \mathrm{C}$. Of the resultant three layers of supernatant, the middle layer, which includes embryo extract, were retrieved, filtered with $0.1 \mu \mathrm{m}$ syringe filter (Sartorius Stedim Biotech, Göttingen, Germany) for sterilization, and stored at $-20^{\circ} \mathrm{C}$ until use. Protein concentration of embryo extract was estimated using Pierce $^{\circledR}$ BCA protein assay kit (Thermo Scientific, Rockford, IL) according to manufacturer's instruction.

\section{Statistical analysis}

The Statistical Analysis System (SAS) software was used to analyze the numerical data. When an analysis of variance (ANOVA) identified a significant main effect, treatments were subsequently compared by the least-square or Duncan's method. $P<0.05$ were regarded as indicative of significant differences.

\section{RESULTS}

\section{Effects of temperatures and basal media on primary cell adherence}

To investigate the effects of temperatures and basal media on primary adherence of blastula embryo-derived blastomeres, we collected blastomeres from the embryos at blastula stage (Figure $1 \mathrm{~A})$, and seeded them in culture dishes filled with DMEM or L15. After seeding, all blastomeres were singly scattered throughout the dishes and some dividing blastomeres were observed (Figure 1B). Then, they were cultured at $28^{\circ} \mathrm{C}, 31^{\circ} \mathrm{C}, 34^{\circ} \mathrm{C}$, or $37^{\circ} \mathrm{C}$ incubator and their primary adherence was evaluated by daily observation. Primary cell adherence was defined when the blastomeres formed the adhered colonies and their growth and outward migration from the colonies were observed (Figure 1C). As the results, 71\% of the trials showed primary adherence in both groups cultured in DMEM and L15 when the blastomeres were cultured at $28^{\circ} \mathrm{C}$. In contrast to this, when the blastomeres were cultured over $31^{\circ} \mathrm{C}, 100 \%$ of the trials showed primary adherence regardless of the type of media with the exception of a group cultured in $\mathrm{L} 15$ at $31^{\circ} \mathrm{C}$ which showed $83 \%$ primary adherence (Figure $2 \mathrm{~A}$ ). In case of the period required for primary cell adherence, significant differences were observed among the treatment groups. The groups cultured at $34^{\circ} \mathrm{C}$ and $37^{\circ} \mathrm{C}$ showed significantly faster primary cell adherence than the groups cultured at $28^{\circ} \mathrm{C}$ and $31^{\circ} \mathrm{C}$ in both media (Figure $2 \mathrm{~B} ; 1.00 \pm 0.00$ to $1.5 \pm 0.58$ vs. $2.25 \pm 0.50$ to $2.50 \pm 0.58$ days, $P<0.05)$. 

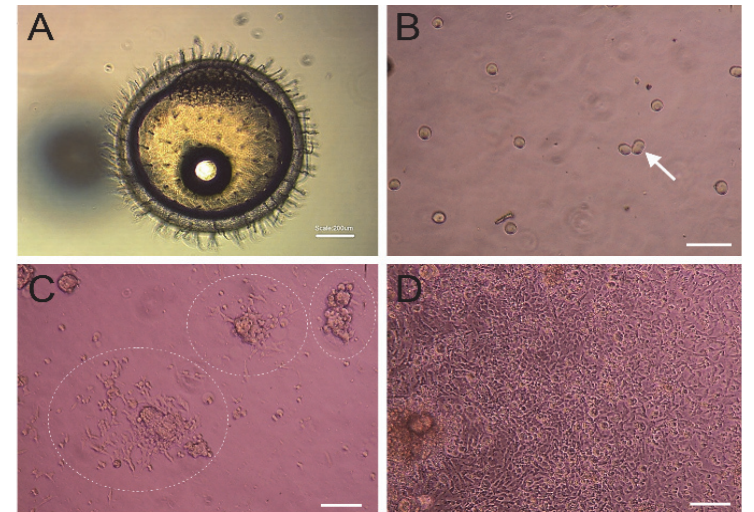

Figure 1. Pictures regarding primary culture of the blastomeres from Oryzias dancena blastula embryos. (A) Blastula embryo 8 h $30 \mathrm{~min}$ after fertilization. (B) Blastomeres seeded to culture medium after being dissociated from the embryos. Arrow indicates a dividing blastomere. (C) Primary adherence and growth of the blastomeres. Dotted circles indicate the cells that show primary adherence and active proliferation. At this time, the cells usually formed the colonies. (D) The cells that reached to 90 to $100 \%$ confluency when the cells were subcultured for the first time. Scale bars $=200 \mu \mathrm{m}$ in A and $100 \mu \mathrm{m}$ in B, C, and D.

A

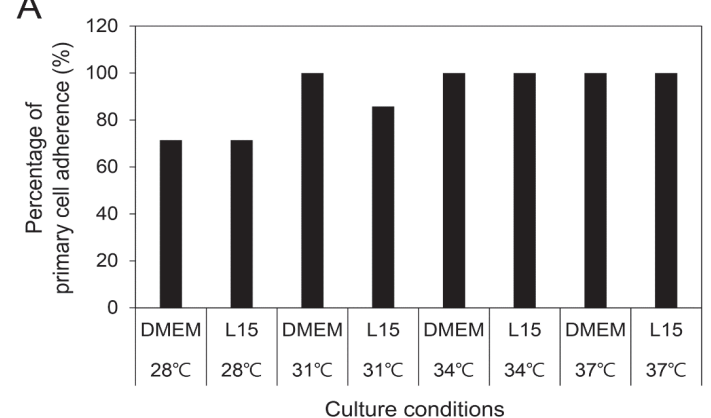

$\mathrm{B}$

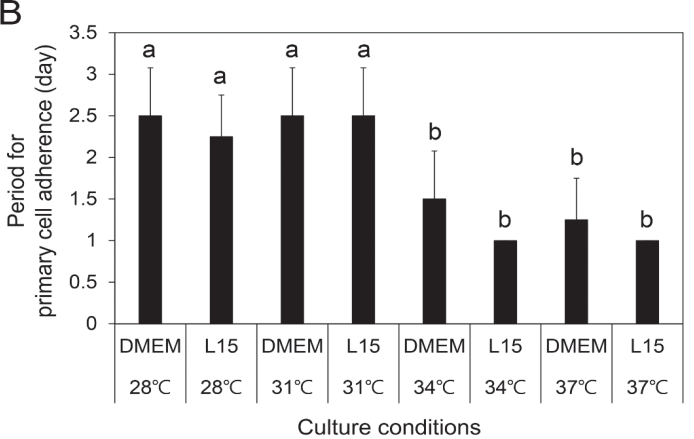

Figure 2. Primary adherence of the blastomeres from Oryzias dancena blastula embryos in culture. (A) Percentage of primary cell adherence. The number of trials in which the cells showed primary adherence were presented as the percentage of a total number of trials. No significant difference was detected among the groups. (B) Period for primary cell adherence. Data are expressed as mean \pm standard of deviation (SD). ${ }^{a b}$ Different letters indicate significant differences, $P<0.05$.

\section{Effects of temperatures and basal media on initial culture}

Next, we examined the effects of temperatures and basal media on initial culture of blastula embryo-derived blastomeres. In this experiments, the first subculture was performed when the cells reached $90-100 \%$ confluency (Figure 1D) and afterward, it was conducted at $80-90 \%$ confluency. As shown in Table 1, significant difference was not detected up to passage 2 in the proportion of subculture among treatment groups. However, the blastomeres cultured in DMEM at $31^{\circ} \mathrm{C}$ showed significantly high proportion of subculture at passage 3,4 , and 5 compared to the other groups ( 0 to $29 \%$ vs. $75 \%, 63 \%$, and $63 \%$ in passage 3, 4, and 5 , respectively) and a cell population in this group was subcultured to passage 8 . The cells cultured in L15 were not cultured beyond passage 2 regardless of culture temperatures with the exception of a case cultured at $31^{\circ} \mathrm{C}$, which was cultured to passage 7 . In the groups cultured at $37^{\circ} \mathrm{C}$, even the cells cultured in DMEM did not grow beyond passage 2 .

\section{DISCUSSION}

In this study evaluating the effects of temperatures and basal media on primary culture of the blastomeres derived from blastula embryos, we demonstrated that both factors influenced to primary cell adherence and initial culture of the blastomeres. Especially, the temperature looked more influential than basal media at least in this experimental design. In cell culture, the optimal temperature depends on the body temperature of the animals from which the cells were derived or the anatomic difference (Freshney, 2010). Therefore, the cells and tissues from human and mouse are usually cultured in $37^{\circ} \mathrm{C}$ according to their body temperature (Wang et al., 2017). But, in some cases like testis tissues, they are cultured in less than $37^{\circ} \mathrm{C}$ based on the anatomic difference (Gohbara et al., 2010). In contrast to mammalian species, however, fish can acclimate to a wide range of temperature as a poikilothermic vertebrate and thus the cultured cells from fish can also tolerate a wide range of temperature (Lannan et al., 1984; Qin et al., 2006; Ryu et al., 2016). However, it has been reported that the alteration of temperature in culture of fish cells is able to influence the physiology of the cells (Lannan et al., 1984). This indicates that determination of temperature is a quite important work for fish cell culture.

In our results, $31^{\circ} \mathrm{C}$ was the optimal temperature for primary culture of blastula embryo-derived blastomeres in that high proportion of primary cell adherence and subculture was achieved in this temperature. The previous studies regarding ESC culture in $O$. latipes have used $28^{\circ} \mathrm{C}$ culture temperature (Hong et al., 1996; Yi et al., 2009). This 
Table 1. Outcomes of primary cultures depending on different culture conditions

\begin{tabular}{|c|c|c|c|c|c|c|c|c|c|c|}
\hline \multirow{2}{*}{$\begin{array}{l}\text { Temp. } \\
\left({ }^{\circ} \mathrm{C}\right)\end{array}$} & \multirow{2}{*}{ Media } & \multirow{2}{*}{$\begin{array}{c}\text { No. } \\
\text { of trials }\end{array}$} & \multicolumn{8}{|c|}{ Number $(\%)^{\mathrm{a}}$ of trials subcultured to } \\
\hline & & & Passage 1 & Passage 2 & Passage 3 & Passage 4 & Passage 5 & Passage 6 & Passage 7 & Passage 8 \\
\hline \multirow{2}{*}{28} & DMEM & 7 & $2(29)$ & $1(14)$ & $1(14)^{\mathrm{c}}$ & $1(14)^{\mathrm{c}}$ & $1(14)^{\mathrm{c}}$ & $0(0)$ & $0(0)$ & $0(0)$ \\
\hline & L15 & 7 & $3(43)$ & $2(29)$ & $0(0)^{\mathrm{c}}$ & $0(0)^{\mathrm{c}}$ & $0(0)^{\mathrm{c}}$ & $0(0)$ & $0(0)$ & $0(0)$ \\
\hline \multirow{2}{*}{31} & DMEM & 8 & $7(88)$ & $7(88)$ & $6(75)^{\mathrm{b}}$ & $5(63)^{\mathrm{b}}$ & $5(63)^{\mathrm{b}}$ & $3(38)$ & $1(13)$ & $1(13)$ \\
\hline & L15 & 7 & $6(86)$ & $4(57)$ & $2(29)^{\mathrm{c}}$ & $2(29)^{\mathrm{c}}$ & $2(29)^{\mathrm{c}}$ & $2(29)$ & $1(14)$ & $0(0)$ \\
\hline \multirow{2}{*}{34} & DMEM & 7 & $5(71)$ & $2(29)$ & $1(14)^{\mathrm{c}}$ & $1(14)^{\mathrm{c}}$ & $1(14)^{\mathrm{c}}$ & 1 (14) & $0(0)$ & $0(0)$ \\
\hline & L15 & 8 & $5(63)$ & $2(25)$ & $0(0)^{\mathrm{c}}$ & $0(0)^{\mathrm{c}}$ & $0(0)^{\mathrm{c}}$ & $0(0)$ & $0(0)$ & $0(0)$ \\
\hline \multirow{2}{*}{37} & DMEM & 7 & $3(43)$ & $2(29)$ & $0(0)^{\mathrm{c}}$ & $0(0)^{\mathrm{c}}$ & $0(0)^{\mathrm{c}}$ & $0(0)$ & $0(0)$ & $0(0)$ \\
\hline & L15 & 8 & $4(50)$ & $3(38)$ & $0(0)^{\mathrm{c}}$ & $0(0)^{\mathrm{c}}$ & $0(0)^{\mathrm{c}}$ & $0(0)$ & $0(0)$ & $0(0)$ \\
\hline
\end{tabular}

${ }^{a}$ Percentage of the number of trials

${ }^{\mathrm{bc}}$ Different letters within the same column indicate significant differences, $P<0.05$.

corresponds to a previous report describing that the optimal fish cell growth in in vitro culture occurs at the temperature slightly higher than that for fish growth (Grunow et al., 2011). However, our previous results regarding $O$. dancena ESC derivation showed low efficiency of continuous cell line derivation from the culture of blastula embryo-derived blastomeres even through same culture temperature of $28^{\circ} \mathrm{C}$ was used (Lee et al., 2013). These suggest that the optimal culture temperature for cell culture should be empirically determined in a certain fish species.

Significant reduction of the period required for primary cell adherence was observed in the groups cultured in more than $34^{\circ} \mathrm{C}$ regardless of the type of basal media. However, this faster adhesion did not influence to any of further growth indicating that high temperature over $34^{\circ} \mathrm{C}$ is not effective to primary culture of blastomeres derived from blastula embryos. Nevertheless, our results showed that the blastomeres derived from $O$. dancena blastula embryos were able to grow in a wide range of temperatures from $28^{\circ} \mathrm{C}$ to $37^{\circ} \mathrm{C}$ at least up to passage 2 . Furthermore, the fact that the cells were able to grow in the culture condition using $37^{\circ} \mathrm{C}$ is another interesting point to be studied.

In the comparison between two basal media, a higher proportion of subculture was achieved in the cells cultured in DMEM than in $\mathrm{L} 15$ at $31^{\circ} \mathrm{C}$. The major difference between two media except for the detailed formula of each basal media was the presence of HEPES in DMEM because DMEM is able to control its physiological $\mathrm{pH}$ in air atmosphere with the help of HEPES whereas L15 regulates the physiological $\mathrm{pH}$ itself (Will et al., 2011). However, HEPES was not likely to have a growth-promoting effect, but rather, the difference in the formula between two basal media might contribute to the different growth of the cells cultured in two media. However, in this experiments, many unrefined supplements such as FBS, fish serum, and embryo extract were added in culture media and thus simple comparison of the components between two media might not be worthwhile in current status. The advanced culture system using serum- and extract-free media will be able to help reveal this difference.

In conclusion, we found that the culture condition using $31^{\circ} \mathrm{C}$ temperature and DMEM was effective for primary culture of the blastomeres derived from $O$. dancena embryos at blastula stage. The results from this study will be able to provide a fundamental information for derivation of pluripotent ESCs in various fish species in addition to $O$. dancena.

\section{ACKNOWLEDGEMENT}

This work was supported by a Research Grant of Pukyong National University (Year 2017).

\section{REFERENCES}

Barman AS, Lal KK, Rathore G, Mohindra V, Singh RK, Singh A, Khare P and Lal B. 2014. Derivation and characterization of ES-like cell line from Indian catfish Heteropneustes fossilis blastulas. Sci World J. 2014, 427497.

Bejar J, Hong Y and Alvarez MC. 2002. An ES-like cell line from the marine fish sparus aurata: Characterization and chimaera production. Transgenic Res. 11, 279 - 289.

Bradley A, Evans M, Kaufman MH and Robertson E. 1984. Formation of germ-line chimeras from embryo-derived teratocarcinoma cell lines. Nature. 309, 255-256.

Chen SL, Ye HQ, Sha ZX and Hong Y. 2003. Derivation of a pluripotent embryonic cell line from red sea bream blastulas. J Fish Biol. 63, $795-805$.

Chen SL, Sha ZX, Ye HQ, Liu Y. Tian YS, Hong Y and Tang QS. 
2007. Pluripotency and chimera competence of an embryonic stem cell line from the sea perch (Lateolabrax japonicus). Mar Biotechnol (NY). 9, $82-91$.

Cho YS, Lee SY, Kim DS and Nam YK. 2010. Tolerance capacity to salinity changes in adult and larva of Oryzias dancena, a euryhaline medaka. Korean J Ichthyol. 22, 9-16.

Dash C, Routray P, Tripathy S, Verma DK, Guru BC, Meher PK, Nandi S and Eknath AE. 2010. Derivation and characterization of embryonic stem-like cells of Indian major carp Catla catla. J Fish Biol. 77, 1096 - 1113.

Evans MJ and Kaufman MH. 1981. Establishment in culture of pluripotential cells from mouse embryos. Nature. 292, 154-156.

Fan Z, Liu L, Huang X, Zhao Y, Zhou L, Wang D and Wei J. 2017. Establishment and growth response of Nile tilapia embryonic stem-like cell lines under feeder-free condition. Dev Growth Differ. 59, 83-93.

Freshney RI. 2010. Culture of animal cells: a manual of basic technique and specialized applications. 6th ed. Wiley-Blackwell, Hoboken, NJ, US.

Gohbara A, Katagiri K, Sato T, Kubota Y, Kagechika H, Araki Y, Araki $\mathrm{Y}$ and Ogawa T. 2010. In vitro murine spermatogenesis in an organ culture system. Biol Reprod. 83, 261-267.

Goswami M, Lakra WS, Yadav K and Jena JK. 2012. Development of an ES-like cell culture system (RESC) from rohu, Labeo rohita (Ham.). Fish Physiol Biochem. 38, 1775-1783.

Grunow B, Noglick S, Kruse C and Gebert M. 2011. Isolation of cells from Atlantic sturgeon Acipenser oxyrinchus oxyrinchus and optimization of culture conditions. Aquat Biol. 14, 67 - 75.

Ho SY, Goh CW, Gan JY, Lee YS, Lam MK, Hong N, Hong Y, Chan WK and Shu-Chien AC. 2014. Derivation and long-term culture of an embryonic stem cell-like line from zebrafish blastomeres under feeder-free condition. Zebrafish. 11, 407-420.

Holen E and Hamre K. 2004. Towards obtaining long term embryonic stem cell like cultures from a marine flatfish, Scophthalmus maximus. Fish Physiol Biochem. 29, 245 - 252.

Holen E, Kausland A and Skjaerven K. 2010. Embryonic stem cells isolated from atlantic cod (Gadus morhua) and the developmental expression of a stage-specific transcription factor ac-pou2. Fish Physiol Biochem. 36, 1029 - 1039.

Hong Y, Winkler C and Schartl M. 1996. Pluripotency and differentiation of embryonic stem cell lines from the medakafish (Oryzias latipes). Mech Dev. 60, 33-44.

Hong Y, Winkler C and Schartl M. 1998. Production medakafish chimeras from a stable embryonic stem cell line. Proc Natl Acad Sci USA. 5, 93-104.
Inoue K and Takei Y. 2003. Asian medaka fishes offer new models for studying mechanisms of seawater adaptation. Comp Biochem Physiol B Biochem Mol Biol. 136, 635-645.

Lannan CN, Winton JR and Fryer JL. 1984. Fish cell lines: establishment and characterization of nine cell lines from salmonids. In Vitro. 20, 671-676.

Lee D, Kim MS, Nam YK, Kim DS and Gong SP. 2013. Establishment and characterization of permanent cell lines from Oryzias dancena embryos. Fish Aquat Sci. 16, 177-185. Lee D, Ryu JH, Lee ST, Nam YK, Kim DS and Gong SP. 2015. Identification of embryonic stem cell activities in an embryonic cell line derived from marine medaka (Oryzias dancena). Fish Physiol Biochem. 41, 1569-1576.

Martin GR. 1981. Isolation of a pluripotent cell line from mouse embryo cultures in medium conditioned by teratocarcinoma stem cells. Proc Nat Acad Sci USA. 78, 7634-7638.

Parameswaran V, Shukla R, Bhonde R and Hameed AS. 2007. Development of a pluripotent ES-like cell line from Asian sea bass (Lates calcarifer)--an oviparous stem cell line mimicking viviparous ES cells. Mar Biotechnol. 9, 766 - 775.

Qin QW, Wu TH, Jia TL, Hegde A and Zhang RQ. 2006. Development and characterization of a new tropical marine fish cell line from grouper, Epinephelus coioides susceptible to iridovirus and nodavirus. J Virol Meth. 131, 58-64.

Robl JM, Wang Z, Kasinathan P and Kuroiwa Y. 2007. Transgenic animal production and animal biotechnology. Theriogenology. 67, 127 - 133. Ryu JH, Kim HJ, Bae SS, Jung CG and Gong SP. 2016. Isolation and in vitro culture of primary cell populations derived from ovarian tissues of the rockfish, Sebastes schlegeli. Fish Aquat Sci. 19, 9.

Song HY, Nam YK, Bang IC and Kim DS. 2009. Embryogenesis and early ontogenesis of a marine medaka, Oryzias dancena. Korean J Ichthyol. 21, 227 - 238.

Wang J, Wei Y, Zhao S, Zhou Y, He W, Zhang Y and Deng W. 2017. The analysis of viability for mammalian cells treated at different temperatures and its application in cell shipment. PLoS One. 12, e0176120.

Will MA, Clark NA and Swain JE. 2011. Biological pH buffers in IVF: help or hindrance to success. J Assist Reprod Genet. 28, 711-724.

Yasui GS, Fujimoto T, Sakao S, Yamaha E and Arai K. 2011. Production of loach (Misgurnus anguillicaudatus) germ-line chimera using transplantation of primordial germ cells isolated from cryopreserved blastomeres. J Anim Sci. 89, 2380-2388.

Yi M, Hong N and Hong Y. 2009. Generation of medaka fish haploid embryonic stem cells. Science. 326, 430-433. 